\title{
HaCaT Cells as a Reliable In Vitro Differentiation Model to Dissect the Inflammatory/Repair Response of Human Keratinocytes
}

\author{
Irma Colombo, ${ }^{1}$ Enrico Sangiovanni, ${ }^{1}$ Roberta Maggio, ${ }^{2}$ Carlo Mattozzi, ${ }^{3}$ Stefania Zava, \\ Yolanda Corbett, ${ }^{1}$ Marco Fumagalli, ${ }^{1}$ Claudia Carlino, ${ }^{4}$ Paola Antonia Corsetto, ${ }^{1}$ \\ Diletta Scaccabarozzi, ${ }^{1}$ Stefano Calvieri, ${ }^{3}$ Angela Gismondi, ${ }^{5}$ Donatella Taramelli, ${ }^{1}$ \\ and Mario Dell'Agli ${ }^{1}$ \\ ${ }^{1}$ Dipartimento di Scienze Farmacologiche e Biomolecolari, Università degli Studi di Milano, Via Balzaretti 9, 20133 Milano, Italy \\ ${ }^{2}$ Dipartimento di Medicina Sperimentale, Università di Roma La Sapienza, Viale Regina Elena 324, 00161 Roma, Italy \\ ${ }^{3}$ Dipartimento di Medicina Interna e Specialità Mediche, UOC di Clinica Dermatologica, Università di Roma "Sapienza", \\ Viale del Policlinico 155, 00161 Roma, Italy \\ ${ }^{4}$ Center for Life Nano Science@Sapienza, Istituto Italiano di Tecnologia, Viale Regina Elena 291, 00161 Roma, Italy \\ ${ }^{5}$ Dipartimento di Medicina Molecolare, Università di Roma La Sapienza, Viale Regina Elena 291, 00161 Roma, Italy
}

Correspondence should be addressed to Donatella Taramelli; donatella.taramelli@unimi.it

Received 9 June 2017; Revised 27 September 2017; Accepted 18 October 2017; Published 17 December 2017

Academic Editor: Juarez A. S. Quaresma

Copyright ( 2017 Irma Colombo et al. This is an open access article distributed under the Creative Commons Attribution License, which permits unrestricted use, distribution, and reproduction in any medium, provided the original work is properly cited.

\begin{abstract}
Cultured primary human keratinocytes are frequently employed for studies of immunological and inflammatory responses; however, interpretation of experimental data may be complicated by donor to donor variability, the relatively short culture lifetime, and variations between passages. To standardize the in vitro studies on keratinocytes, we investigated the use of HaCaT cells, a long-lived, spontaneously immortalized human keratinocyte line which is able to differentiate in vitro, as a suitable model to follow the release of inflammatory and repair mediators in response to TNF $\alpha$ or IL-1 $\beta$. Different treatment conditions (presence or absence of serum) and differentiation stimuli (increase in cell density as a function of time in culture and elevation of extracellular calcium) were considered. ELISA and Multiplex measurement technologies were used to monitor the production of cytokines and chemokines. Taken together, the results highlight that $\mathrm{Ca}^{2+}$ concentration in the medium, cell density, and presence of serum influences at different levels the release of proinflammatory mediators by HaCaT cells. Moreover, HaCaT cells maintained in low $\mathrm{Ca}^{2+}$ medium and $80 \%$ confluent are similar to normal keratinocytes in terms of cytokine production suggesting that $\mathrm{HaCaT}$ cells may be a useful model to investigate anti-inflammatory interventions/therapies on skin diseases.
\end{abstract}

\section{Introduction}

The skin is a continuously self-renewing organ that dynamically manages the outside-inside-outside relationships of the human body and actively participates in the host defenses [1]. Keratinocytes (KCs) represent $95 \%$ of the epidermal cells. Primarily, they play the structural and barrier function of the epidermis, but their role in the initiation and perpetuation of skin inflammatory and immunological responses, and wound repair, is also well recognized [2].

Under homeostatic conditions, KCs differentiate and mature from proliferating nucleated basal cells to the highly differentiated, nucleus-free corneocytes. Each stage of differentiation is characterized by the expression of structural proteins, such as keratins (K) and lipids [3, 4]. For example, the expression of $\mathrm{K} 5$ and $\mathrm{K} 14$ is restricted to the basal layer, 
whereas $\mathrm{K} 1$ and K10 appear on more differentiated suprabasal cells [4], and involucrin, loricrin, and keratolinin, in the cells of the uppermost spinous layer [1]. Terminal differentiation is driven by various cytokines and growth factors, and it is typically associated with the formation of the peripheral envelopes, rich in proteins and lipids [3,4]. The calcium $\left(\mathrm{Ca}^{2+}\right)$ gradient in the epidermis, increasing from the basal to the granular layer, represents one of the most important triggers of KC differentiation [4].

Resting KCs produce epidermal growth factor receptor (EGFR) ligands and vascular endothelial growth factor (VEGF), but when activated by bacterial products or by direct damage by UV light or chemicals, the expression of cytokines and chemokines changes $[5,6]$. In skin diseases, such as psoriasis [7] or atopic dermatitis [8], the cytokine/ chemokine network is even more complex and autocrine/ paracrine loops are described [2].

Cultured human KCs are frequently employed for studies of $\mathrm{KC}$ functions in chronic inflammatory skin diseases $[9,10]$. Primary $\mathrm{KCs}$ cultured in vitro at low $\mathrm{Ca}^{2+}$ concentration retain a basal phenotype, and they differentiate upon addition of $\mathrm{Ca}^{2+}>0.1 \mathrm{mM}[11,12]$. However, their use for routine monitoring of the inflammatory response of the inflamed skin presents major drawbacks. Firstly, fresh human KCs require supplementary growth factors to survive and proliferate in vitro; secondly, once induced to differentiate, they rapidly die and do not allow long-term investigation of the differentiation signals [13]. Moreover, donor-to-donor variability in growth characteristics and in vitro responses, different plating efficiencies, the short lifetime in culture, and the changes in proliferation and differentiation characteristics with increasing number of passages, complicates the interpretation of experimental data.

To minimize these problems, the spontaneously immortalized human $\mathrm{KC}$ cell line $\mathrm{HaCaT}$ from adult skin has been proposed as a model for the study of $\mathrm{KC}$ functions. HaCaT is a nontumorigenic monoclonal cell line, adapted to longterm growth without feed-layer or supplemented growth factors [13, 14]; it exhibits normal morphogenesis and expresses all the major surface markers and functional activities of isolated KC [14]; upon stimulation, HaCaT cells differentiate and express specific markers of differentiation, such as K14, K10, and involucrin. They can also form stratified epidermal structure [15], but they can revert, back and forth, between a differentiated and a basal state upon changes in $\mathrm{Ca}^{2+}$ concentration in the medium [16]; they retain the capacity to reconstitute a well-structured epidermis after transplantation in vivo [17].

The aim of the present study was to investigate and optimize the best conditions to use $\mathrm{HaCaT}$ cells as a reliable in vitro model to evaluate, at different stages of differentiation, the production of proinflammatory mediators, chosen among those mostly involved in skin inflammation and angiogenesis.

\section{Materials and Methods}

2.1. Cell Culture. HaCaT cells, spontaneously immortalized human keratinocyte line [15], were kindly provided by Cell
Line Service GmbH (Eppelheim, Germany) and cultured in $5 \% \mathrm{CO}_{2}$ at $37^{\circ} \mathrm{C}$ in regular Dulbecco's Modified Eagle's Medium (DMEM) (Euroclone S.P.A., Milan, Italy) containing $1.8 \mathrm{mM} \mathrm{Ca}^{2+}$, or with DMEM (Gibco, Life Technologies, Carlsbad, CA, USA) at low concentration of $\mathrm{Ca}^{2+}(0.07 \mathrm{mM})$. Both media were supplemented with $10 \%$ heat-inactivated fetal bovine serum, glutamine $(2 \mathrm{mM})$, penicillin $(100 \mathrm{U} / \mathrm{ml})$ (Euroclone), and streptomycin (100 mg/ml) (Euroclone). For all experiments, cells were seeded at a density of $5.7 \times 10^{3}$ cells $/ \mathrm{cm}^{2}$ and cultured with DMEM at high or low $\mathrm{Ca}^{2+}$ concentration for 6 or 14 days. The samples were labeled as follows: A6, cells cultured for 6 days with low $\mathrm{Ca}^{2+}$ concentration $(0.07 \mathrm{mM})$ and tested when $80 \%$ confluent; A14, cells cultured for 14 days with low $\mathrm{Ca}^{2+}$ concentration $(0.07 \mathrm{mM})$ and tested when overconfluent; C6, cells cultured for 6 days with high $\mathrm{Ca}^{2+}$ concentration $(1.8 \mathrm{mM})$ and tested when $80 \%$ confluent; and C14, cells cultured for 14 days with high $\mathrm{Ca}^{2+}$ concentration $(1.8 \mathrm{mM})$ and tested when overconfluent. The medium was changed every 2 days. A flow chart with details of the experimental protocol is reported in Figure 1.

2.2. Isolation of Human Keratinocytes from Skin Biopsies. Primary KCs were isolated from nonlesional skin biopsies obtained from adult psoriatic patients not receiving either topical or systemic therapies for at least 6 months, or at the time of sample collection. To separate the epidermal layer from the basement membrane, the $0.4 \mathrm{~mm}$ punch biopsy was treated with dispase (Gibco BRL, Gaithersburg, MD, USA). After $18 \mathrm{~h}$ at $4^{\circ} \mathrm{C}$, the epidermal sheet was separated mechanically and dissociated with TrypLE (Gibco BRL, Gaithersburg, MD, USA) for $20 \mathrm{~min}$ at $37^{\circ} \mathrm{C}$. The obtained primary cells were then plated on 6-well tissue culture plates (Costar), precoated with coating matrix (type I collagen, Gibco BRL), cultured using a specific keratinocyte-serumfree media at low $\mathrm{Ca}^{2+}$ concentration $(<0.07 \mathrm{mM})$, and supplemented with human keratinocyte growth factors (Gibco BRL). When the monolayer reached 60\%-70\% confluence, cells were split by trypsinization. For all the experiments, keratinocyte cultures between the third and fourth passages were used. Informed consent was obtained from all donors providing tissue samples, and ethical approval was obtained from the Ethics Committee of " $\mathrm{La}$ Sapienza” University, Rome, Italy.

2.3. Cell Proliferation Assay. The proliferation of HaCaT cells was determined at the indicated intervals using the MTT colorimetric assay as described [18]. This test is based on the ability of succinic dehydrogenase of living cells to reduce the yellow salt MTT (3-(4,5-dimethylthiazol-2-yl-2,5-diphenyltetrazolium bromide)) (Sigma-Aldrich, St. Louis, MO, USA) to a purple-blue insoluble formazan precipitate. Experiments were performed in 96-well plates containing a final volume of $100 \mu \mathrm{l}$ of medium/well. Cells were seeded at an initial density of $1.0 \times 10^{4}$ cells $/ \mathrm{cm}^{2}$, and, after $1,6,9$, and 14 days, incubation medium was removed and replaced by $100 \mu \mathrm{l}$ of fresh medium. Then, $10 \mu \mathrm{l}$ of stock MTT solution $(5 \mathrm{mg} / \mathrm{ml}$ in PBS) was added and plates were incubated at $37^{\circ} \mathrm{C}$ for $4 \mathrm{~h}$. Finally, $100 \mu \mathrm{l}$ of $10 \%$ sodium dodecyl sulfate (SDS) (Sigma-Aldrich, St. Louis, MO, USA), in $0.01 \mathrm{M} \mathrm{HCl,}$ 


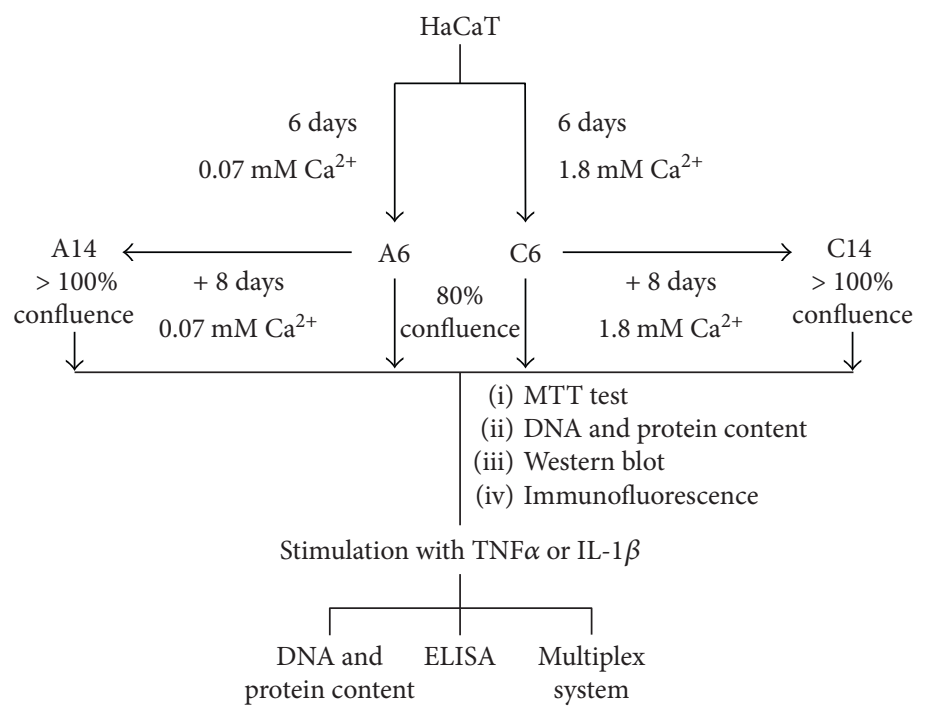

Figure 1: A flow chart with details of the experimental protocol performed on $\mathrm{HaCaT}$ cells.

was added to each well and the amount of formazan formed was measured at $540 \mathrm{~nm}$ using a Benchmark microplate reader (Bio-Rad, Richmond, CA, USA). Sixteen wells per time-point were analyzed in three independent experiments.

2.4. Cell Stimulation. For the stimulation of HaCaT cells, an amount of $1.0 \times 10^{4}$ cells/well in $500 \mu \mathrm{l}$ were seeded in 24-well plate and cultured in low or high $\mathrm{Ca}^{2+}$ medium, with medium changes every two days. After 6 or 14 days, the medium was removed and replaced with $250 \mu \mathrm{L}$ of medium or serum-free medium, supplemented with TNF $\alpha(10 \mathrm{ng} / \mathrm{ml})$ or IL-1 $\beta$ (10 ng/ml) (PeproTech EC, Ltd., London, UK).

After different lengths of time $\left(6,24\right.$, or 48 hours) at $37^{\circ} \mathrm{C}$, the supernatants from two wells for each different treatment and time were pooled in a single tube and frozen at $-20^{\circ} \mathrm{C}$ to be subsequently analyzed for the presence of cytokines, chemokines, and growth factors. The cell monolayers were then washed twice with PBS, $\mathrm{Ca}^{2+}$, and magnesium-free medium, dried, and stored at $-20^{\circ} \mathrm{C}$ for the analysis of DNA content.

For the stimulation of keratinocytes from skin biopsies, $8-10 \times 10^{4}$ cells $/ \mathrm{cm}^{2}$ in $3 \mathrm{ml}$ were seeded in 6 -well plate and cultured in low $\mathrm{Ca}^{2+}$ medium, with medium changes every two days. When the cells reached $60 \%-70 \%$ confluence, the medium was removed and replaced with $3 \mathrm{ml}$ of serum-free medium, supplemented with $\mathrm{TNF} \alpha(10 \mathrm{ng} / \mathrm{ml})$. After 48 hours of incubation at $37^{\circ} \mathrm{C}$, the supernatant was collected, frozen at $-80^{\circ} \mathrm{C}$, and subsequently analyzed for the presence of cytokines, chemokines, and growth factor as described in the multiplex system section.

\subsection{Release of Inflammatory Mediators}

2.5.1. ELISA. The release of CXCL8/IL8 and VEGF from $\mathrm{HaCaT}$ cells was quantified by using two different high sensitivity human ELISA set (Peprotech, Rocky Hill, NJ, USA) following the method described below. Briefly, Corning 96well EIA/RIA plates from Sigma-Aldrich (Milan, Italy) were coated with the antibodies provided, overnight at $4^{\circ} \mathrm{C}$. Matrix metalloproteinase-9 (MMP-9) secretion from HaCaT cells was evaluated by a different ELISA set (RayBio ${ }^{\circledR}$ Human MMP-9 ELISA kit, Norcross, GA) using a precoated 96-well plate, supplied with the kit. In all the three cases, $300 \mu \mathrm{l}$ of samples was transferred in duplicate into wells at room temperature for 2 hours. The results were detected by spectroscopy (signal read $450 \mathrm{~nm}, 0.1 \mathrm{~s}$, by VictorTM X3) using biotinylated and streptavidin-HRP conjugate antibodies, evaluating 3,5,3,59-tetramethylbenzidine (TMB) substrate reaction. The quantification of analytes was done using an optimized standard curve supplied with the ELISA sets. The data are expressed as pg/10 ${ }^{6}$ cells. Results are mean \pm SD of at least three independent cell culture experiments in duplicate.

2.5.2. Bioplex Multiplex System. Supernatants obtained from $\mathrm{HaCaT}$ cells and from primary keratinocytes, stimulated or not with $\mathrm{TNF} \alpha(10 \mathrm{ng} / \mathrm{ml})$ for 48 hours, were analyzed for the presence of chemokines, cytokines, and growth factors. Regarding chemokines, we assayed CXC chemokine ligands (CXCL1/GRO, CXCL10/IP10, CXCL12/SDF-1, and CX3CL1/ fractalkine) and CC chemokine ligands (CCL2/MCP1, CCL3/ MIP1a, CCL4/MIP1b, CCL5/RANTES, CCL7/MCP3, CCL1 1/eotaxin, and CCL22/MDC). Among cytokines, we assayed TGF $\alpha, \operatorname{TNF} \beta$, IFN- $\alpha 2$, IFN- $\gamma$, G-CSF, GM-CSF, IL-10, IL12p70, IL-15, and IL-33. All factors were quantified simultaneously by Bio-Plex Pro human cytokine assays according to the manufacturer's instructions (Bio-Plex Bio-Rad Laboratories, CA, USA). The analyte levels were determined using Bio-Plex array reader (Luminex, Austin, TX, USA) and the Bio-Plex manager software. The relative concentration of each analyte was obtained through the establishment of standard curves, and results are expressed as pg/10 6 cells.

2.6. Analysis of DNA Content. Analysis of DNA content was performed using the commercial kit fluorimetric "FluoReporter Blue Fluorometric DNA Quantitation Kit” (Molecular Probes, Life Technologies, Carlsbad, CA, USA) in 96-well 
plates following the manufacturer's instructions. Plates with treated HaCaT cells were thawed, and $200 \mu \mathrm{L}$ of distilled $\mathrm{H}_{2} \mathrm{O}$ was added to each well. After three cycles of freezingthawing, $100 \mu \mathrm{l}$ was then transferred into a 96-well plate and used for the assay. In parallel, the standard calibration curve was made using increasing concentrations $(0-1000 \mathrm{ng} / 100 \mu \mathrm{l})$ of DNA from calf thymus diluted in TE buffer $\left(10 \mathrm{mM}\right.$ Tris base, $1 \mathrm{mM}$ EDTA in distilled $\mathrm{H}_{2} \mathrm{O}$ entire solution with a pH equal to 7.4). The amount of $100 \mu \mathrm{L}$ of Hoechst dye was then added to each well containing the sample or standard, previously diluted 1:400 in TNE buffer $(10 \mathrm{mM}$ Tris, $2 \mathrm{M} \mathrm{NaCl}, 1 \mathrm{mM}$ EDTA with a final $\mathrm{pH}$ of 7.4 , and $2 \mathrm{mM}$ sodium azide). The emitted fluorescence was measured with microplate reader TECAN F500 (Tecan, Maennedorf, Switzerland) using excitation and emission wavelengths at $346 \mathrm{~nm}$ and $460 \mathrm{~nm}$, respectively. The DNA content was calculated by interpolation of the absorbance of the samples on the calibration curve. The DNA content was expressed as $\mu \mathrm{g} \mathrm{DNA} / 10^{6}$ cells counted, in each well, using a Burker chamber and trypan blue.

2.7. Protein Extraction and Analysis of Protein Content. For total protein extraction, $\mathrm{HaCaT}$ cells were cultured for 6 or 14 days with proper medium. For each time-point of the differentiation, cells were washed with cold PBS and lysed in RIPA lysis buffer $(0.5 \%$ deoxycholate, $1 \%$ Nonidet P- 40 , $0.1 \%$ SDS, $100 \mu \mathrm{g} / \mathrm{ml}$ of phenylmethylsulfonyl fluoride (PMSF), $1 \mathrm{mM} \mathrm{Na} \mathrm{NO}_{4}$, and $8.5 \mu \mathrm{g} / \mathrm{ml}$ of aprotinin, in PBS), shaking for $20 \mathrm{~min}$ at $4^{\circ} \mathrm{C}$. Samples were collected by scraper, incubated for $60 \mathrm{~min}$ at $4^{\circ} \mathrm{C}$, and centrifuged at $12.000 \mathrm{rpm}$ for $15 \mathrm{~min}$ at $4^{\circ} \mathrm{C}$, and the supernatant was collected and frozen at $-20^{\circ} \mathrm{C}$ until use. The soluble proteins in the extract were quantified according to the method described by Lowry et al. [19].

2.8. Western Blot Analysis. For Western blot analysis, $40 \mu \mathrm{l}$ of total protein was separated on $7.5 \%$ SDS-PAGE gel and transferred to a polyvinylidenedifluoride transfer membrane (PVDF) (Bio-Rad, Richmond, CA, USA) for $16 \mathrm{~h}$ at $150 \mathrm{~mA}$, using transfer buffer $(25 \mathrm{mM}$ Tris $\mathrm{HCl}, 190 \mathrm{mM}$ glycine, $20 \%$ methanol, and $0.05 \%$ SDS). The membranes were blocked by incubation in blocking buffer (PBS containing $0.1 \%$ Tween and $5 \%$ dried nonfat milk) for $2 \mathrm{~h}$ and $30 \mathrm{~min}$ at room temperature. Then, membranes were blotted overnight at $4^{\circ} \mathrm{C}$ with various dilutions of primary antibodies, specifically, rabbit polyclonal $\operatorname{IgG}$ anti-involucrin $(1: 2500$; Genetex, Irvine, CA, USA), mouse polyclonal IgG anti-cytokeratin 14 (1:1500; Santa Cruz Biotechnology Inc., Santa Cruz, CA, USA), and rabbit monoclonal IgG anti-cytokeratin 10 ( $1: 10,000$; Genetex, Irvine, CA USA). Mouse monoclonal anti- $\beta$-actin antibody $(1: 6000$; Sigma-Aldrich, St. Louis, MO, USA) was used to normalize gel loading. Blots were washed six times with PBS- $0.1 \%$ Tween and incubated for $1 \mathrm{~h}$ at room temperature with horseradish peroxidaselinked secondary antibodies. Involucrin and K10 were detected with a donkey anti-rabbit IgG (1:10,000; Santa Cruz Biotechnology Inc., Santa Cruz, CA, USA). For K14 and actin, a goat anti-mouse IgG $(1: 10,000$; Santa Cruz Biotechnology Inc., Santa Cruz, CA, USA) was used. All blots were developed by ECL Western blotting detection LiteAblot ${ }^{\circledR}$ plus Kit Reagent (Euroclone S.P.A., Milan, Italy), following the manufacturer's protocol. Immunoreactive proteins were visualized by autoradiography on Hyperfilm ECL (GE Healthcare Life Sciences, UK). The relative intensities of band signals were quantified by digital scanning densitometry, and $\beta$-actin was used to normalize the results to protein content.

2.9. Immunofluorescence. $\mathrm{HaCaT}$ and primary keratinocytes, cultured on 8-well slide chambers, were washed with PBS, fixed, and permeabilized in ice-cold methanol for $5 \mathrm{~min}$. First, cells were incubated in PBS containing $0.1 \%$ bovine serum albumin (BSA) for $10 \mathrm{~min}$, then were incubated with primary antibodies against K10 (rabbit monoclonal IgG anti-cytokeratin 10; 1:200; Genetex, Irvine, CA, USA) for $60 \mathrm{~min}$ in PBS containing 1\% BSA. The cells were subsequently incubated with secondary antibody Alexa Fluor ${ }^{\circledR}$ 488-labeled goat anti-rabbit IgG and Alexa Fluor 488labeled goat anti-mouse IgG $(1: 1000$, Invitrogen, Life Technologies, Carlsbad, CA, USA) for $30 \mathrm{~min}$, respectively. The nuclei of the cells were stained with $4^{\prime}, 6$-diamidino-2-phenylindole (DAPI; Sigma-Aldrich, St. Louis, MO, USA), which specifically recognizes DNA. The slides were observed by using Nikon Eclipse TE200 inverted microscope with immersion objective at 60x magnification and photographed with Nikon digital camera (Nikon, Japan).

2.10. Statistical Analysis. Data are expressed as mean \pm SD of at least three experiments performed in duplicate. Data were analysed by unpaired one-way analysis of variance (ANOVA) followed by Bonferroni post hoc test. Statistical analysis was done using GraphPad Prism 5.0 software (GraphPad Software Inc., San Diego, CA, USA). $p<0.05$ was considered statistically significant.

\section{Results}

3.1. Effect of Extracellular $\mathrm{Ca}^{2+}$ and Cell Density on Proliferation and Differentiation of $\mathrm{HaCaT}$ Cells. To set up and validate HaCaT cells as an in vitro model to study the inflammatory response of human keratinocytes, two known stimuli of KC differentiation, cell density and extracellular $\mathrm{Ca}^{2+}$ concentration, were used. HaCaT cells were plated at the same density in low $(0.07 \mathrm{mM})$ and high $(1.8 \mathrm{mM}) \mathrm{Ca}^{2+}$ medium, and cell proliferation was assessed by both MTT assay and cell counts at day 6 and day 14 .

In low $\mathrm{Ca}^{2+}$ medium, a steady increase in metabolic activity and cell number was observed over time, while in high $\mathrm{Ca}^{2+}$ medium, cell growth was slower. Comparing low to high $\mathrm{Ca}^{2+}$ medium, about $27.5 \%$ and $70.3 \%$ decrease of MTT activity and $40 \%$ and $60 \%$ decrease in cell count were seen at days 6 and 14 , respectively (Figure 2(a) and Table $1 \mathrm{~S}$ ). However, no significant changes in cell morphology were observed in the different conditions. Phase contrast images showed that $\mathrm{HaCaT}$ cells were flat and spread out after 6 days of growth both in low (A6) or high (C6) $\mathrm{Ca}^{2+}$ medium when they were at $80 \%$ confluence; at day 14 both in low (A14) and high (C14) $\mathrm{Ca}^{2+}$ concentration, they became more cubical in shape with higher 

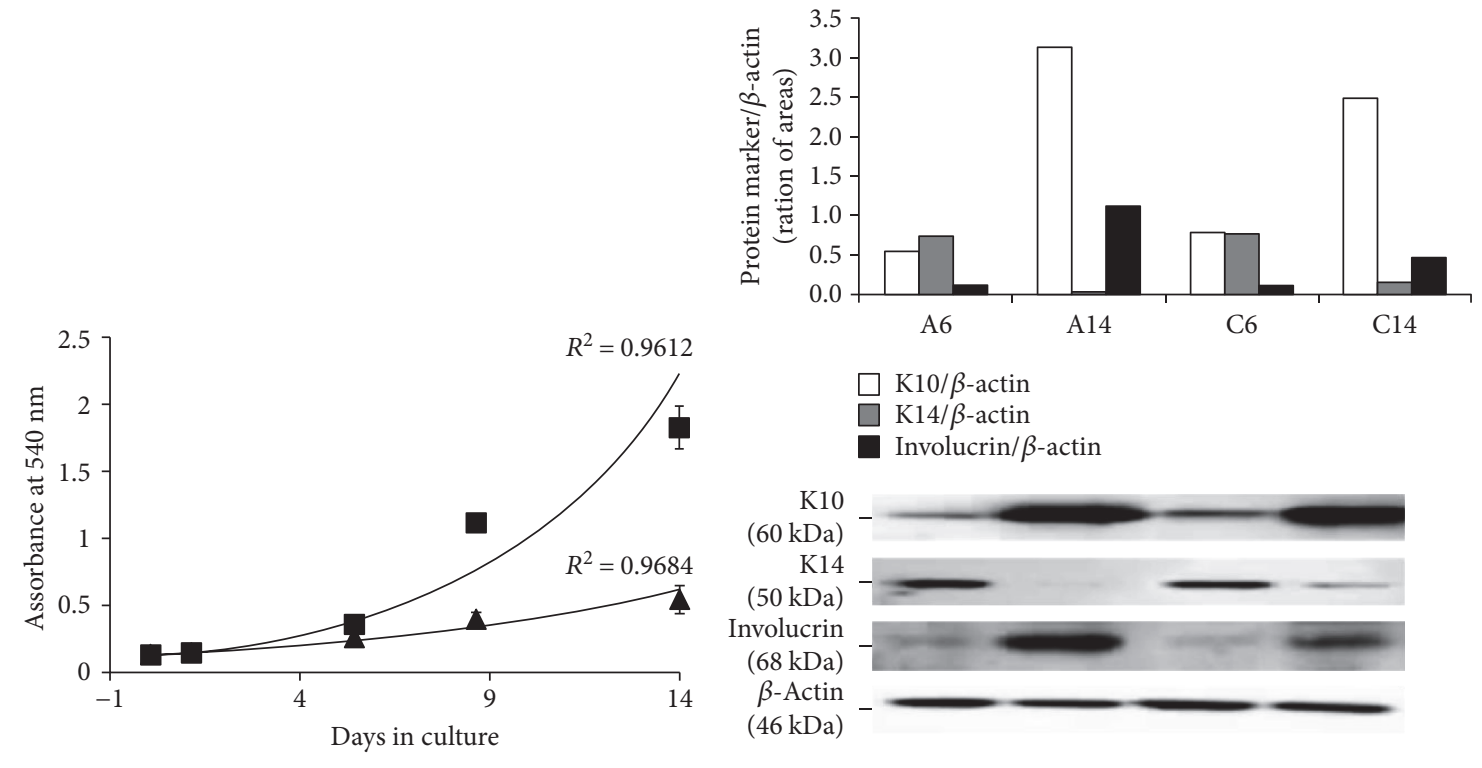

$\boldsymbol{\Delta}$ High calcium $(1.8 \mathrm{mM})$

Low calcium $(0.07 \mathrm{mM})$

(a)

(b)

HaCat cells

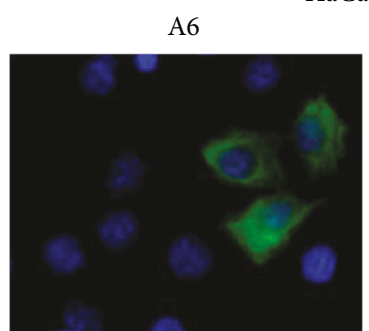

C6

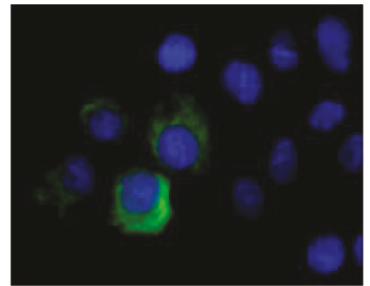

Primary human KC
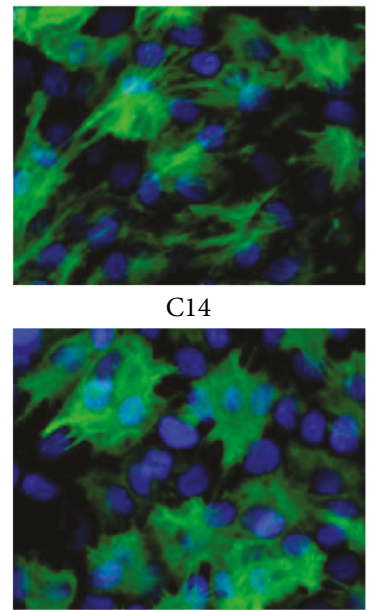

C14

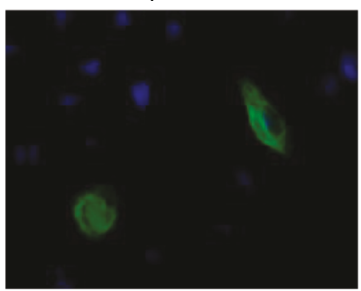

(c)

Figure 2: Proliferation and differentiation of HaCaT cells in low $(0.07 \mathrm{mM})$ and high $(1.8 \mathrm{mM}) \mathrm{Ca}^{2+}$-containing medium. (a) Proliferation of $\mathrm{HaCaT}$ cells plated at the same density $\left(1.0 \times 10^{4}\right.$ cells $\left./ \mathrm{cm}^{2}\right)$ assessed by the MTT assay at 2, 6, 9, and 14 days of incubation. Values represent mean \pm SD of three independent experiments. (b) Western blot analysis of the expression of keratinocyte (KC) differentiation markers (K10, $\mathrm{K} 14$, and involucrin) in HaCaT cells grown in low (a) and high (c) $\mathrm{Ca}^{2+}$-containing medium for 6 (A6 and C6) or 14 (A14 and C14) days. The relative intensities of band signals quantified by digital scanning densitometry are reported in the histogram; $\beta$-actin was used to normalize the results to protein content. This blot is a representative of three independent experiments. (c) Immunofluorescence staining of HaCaT cells, grown in low (A) and high (C) $\mathrm{Ca}^{2+}$-containing medium for 6 (A6 and $\mathrm{C} 6$ ) and 14 (A14 and C14) days, and of primary human KC, grown in low $\mathrm{Ca}^{2+}$-containing medium, with anti-K10 antibodies (magnification: 60x). 
cell-to-cell packing and stratification (Figure S1). As reported in Table 1S, no significant changes were observed in the DNA and protein content in $\mathrm{HaCaT}$ cells grown in medium with different $\mathrm{Ca}^{2+}$ concentrations at the 6th or 14 th day.

The expression of three classical KC differentiation markers (K14, K10, and involucrin) in response to changes in cell density and extracellular $\mathrm{Ca}^{2+}$ levels was assessed by Western blot analysis. Physiologically, the expression of K14 is restricted to the epidermal basal layer, while the presence of K10 and involucrin indicates a more differentiated phenotype.

As shown in Figure 2(b), the expression of K14 was higher in $\mathrm{HaCaT}$ cells at $80 \%$ confluence (day 6) than in overconfluent cells (day 14). At the same time, the levels of $\mathrm{K} 10$ and involucrin increased from day 6 to day 14, confirming the role of cell density on differentiation. Comparing day 6 to day 14 , the fold increase in low $\mathrm{Ca}^{2+}$ medium was more evident for involucrin than for K10 (10.4-fold versus 5.7-fold, resp.), whereas in high $\mathrm{Ca}^{2+}$ medium, the increase was 4.7 -fold versus 3.2 -fold, respectively.

Regarding the effect of $\mathrm{Ca}^{2+}$, at day 6, HaCaT cells showed similar levels of K14, K10, or involucrin in A6 and C6 culture conditions, suggesting that $\mathrm{Ca}^{2+}$ concentration did not significantly influence their expression at $80 \%$ cell confluence (Figure 2(b)). Unexpectedly, at day 14, the levels of both K10 and involucrin were slightly lower in overconfluent $\mathrm{HaCaT}$ cells grown in high compared to low $\mathrm{Ca}^{2+}$ medium (Figure 2(b)). This result could be a consequence of their lower density (Table $1 S$ ).

The acquisition of HaCat cell-differentiated phenotype was confirmed by immunofluorescence experiments (Figure 2(c)). The expression of the differentiation marker K10 increased significantly in $\mathrm{HaCaT}$ cells at day 14 compared to day 6 with almost $100 \%$ cells being positive. In addition, again, no differences in K10 levels were seen between $\mathrm{HaCaT}$ cells grown in low or high $\mathrm{Ca}^{2+}$ medium both in $80 \%$ confluent or overconfluent cells. Control samples without primary antibodies were negative, confirming specificity (data not shown).

The pattern of K10 expression was also evaluated on primary human keratinocytes grown in low $\mathrm{Ca}^{2+}$ and serum-free medium. Interestingly, as shown in Figure 2(c), K10 expression on human primary keratinocytes paralleled $\mathrm{HaCaT}$ cells grown for 6 days in low $\mathrm{Ca}^{2+}$ medium (A6).

\subsection{Release of Inflammatory Mediators from $\mathrm{HaCaT}$ Cells.} $\mathrm{HaCaT}$ cells grown in different culture conditions described above were then utilized to evaluate the production of a series of bioactive molecules, known to be released in the skin during inflammation or repair, both in basal conditions and upon proinflammatory stimulation.

In a first set of experiments, we focused on three main mediators: CXCL8/IL8, VEGF, and MMP-9, which are crucial for inflammatory cell recruitment, angiogenesis, and matrix remodeling, respectively. TNF $\alpha$ and IL- $1 \beta$ were used as stimuli. Influence of serum in the medium was also verified.

The supernatants were obtained from $\mathrm{HaCaT}$ cells plated at the same density in low or high $\mathrm{Ca}^{2+}$ medium and treated, after 6 or 14 days of culture, with $10 \mathrm{ng} / \mathrm{ml} \mathrm{TNF} \alpha$ or IL- $1 \beta$ for
6 or $24 \mathrm{~h}$, as indicated, in absence (Figure 2(a)) or presence of serum (Figure 2(b)). The supernatants were recovered to measure CXCL8/IL8, VEGF, and MMP-9 by ELISA tests. The results are reported in Figure 3 and Figure S2.

Compared to basal levels, the stimulation with $\mathrm{TNF} \alpha$ in the absence of serum induced a significant increase of CXCL8/IL8 and MMP-9, but not of VEGF, both in low and high $\mathrm{Ca}^{2+}$ medium at day 6 (Figure 3(a)). Conversely, the presence of serum during $\mathrm{TNF} \alpha$ treatment at day 6 that did not elicit appreciable effects on CXCL8/IL8 release lowered the TNF $\alpha$-induced MMP-9 release and increased both basal and stimulated levels of VEGF (Figure 3(b)). The concentration fold increase, following TNF $\alpha$ stimulation, was serum independent.

Overall, it appears that the ability of HaCaT cells of releasing these mediators decreased appreciably at day 14 , compared to day 6 , and this is independent on the $\mathrm{Ca}^{2+}$ concentration or the presence of serum (Figure 3). Of note, the MMP-9 amount released at day 6 and day 14 is higher in the absence than in the presence of serum, both in basal condition and upon stimulation.

Similar profiles were observed when cells were stimulated with IL-1 $\beta$ (10 ng/ml) (Figure S2). Higher levels of CXCL8/ IL8, VEGF, and MMP-9 were seen at day 6, compared to day 14 , independently of serum or $\mathrm{Ca}^{2+}$ concentration. In the presence of serum, unstimulated cells produced higher levels of mediators than without serum, and, except for IL8, the increase of VEGF or MMP-9 triggered by IL- $1 \beta$ was not significant.

To extend these observations, different chemokines and cytokines were studied by magnetic bead suspension array using the Bio-Plex Pro technology. The experiments were conducted in serum-free medium to reduce the interferences described in the previous paragraph. As shown in Figures 4(a) and 4(b), the stimulation of HaCaT cells with TNF $\alpha(10 \mathrm{ng} / \mathrm{ml})$ for $48 \mathrm{~h}$ resulted in the upregulation of secretion of almost all the 18 mediators tested in the different culture conditions, although the level of stimulation varied among them. In particular, 6 days of culture in high $\mathrm{Ca}^{2+}$ concentration seem to represent the best combination for optimal production of the majority of mediators, except for CCL4/MIP1b, INF $\alpha 2$, INF $\gamma$, and G-CSF. Of note, CCL7/ MCP3 seemed to be the only cytokine strongly upregulated by TNF $\alpha$ independently of the day of culture and $\mathrm{Ca}^{2+}$ concentration, whereas CCL22/MDC was the only cytokine for which overconfluency, and not $\mathrm{Ca}^{2+}$ levels, contributed to its production. On the contrary, $\mathrm{Ca}^{2+}$ concentration, but not the days in culture, seemed to be particularly relevant for TNF $\alpha$-induced release of GM-CSF. No measurable values for CXCL12/SDF-1, CX3CL1/fractalkine, or IL-33 were obtained from any samples (data not shown).

\subsection{Release of Inflammatory Mediators from Primary Human} Keratinocytes. The release of inflammatory mediators was also measured in primary nonlesional epidermal KCs obtained from psoriatic patients. These cells were grown in low $\mathrm{Ca}^{2+}$ medium and, when tested at $60-70 \%$ confluence, showed K10 expression comparable to A6 HaCaT cells (Figure 2(c)). Regarding the production of cytokines/chemokines, normal 

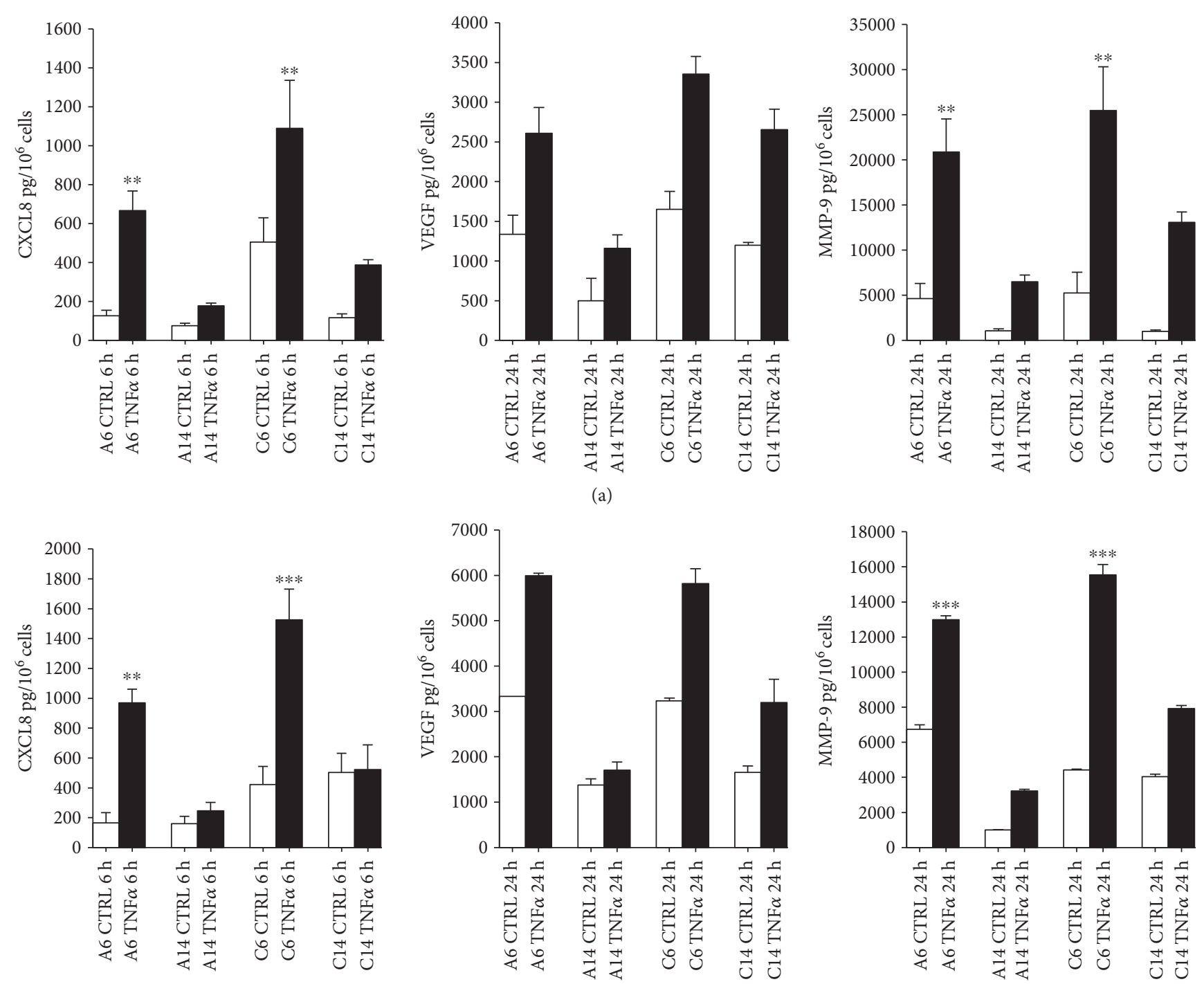

(b)

FIGURE 3: In vitro release of CXCL8/IL8, VEGF, and MMP-9 from HaCaT cells stimulated by TNF $\alpha$ during cell differentiation. The amount of CXCL8/IL8, VEGF, and MMP-9 was measured by ELISA in the supernatants of HaCaT cells plated at the same density $\left(1.0 \times 10^{4} \mathrm{cells} / \mathrm{cm}^{2}\right)$, grown in low (a) and high (C) $\mathrm{Ca}^{2+}$-containing medium for 6 (A6 and C6) or 14 (A14 and C14) days (white bars), and treated with $10 \mathrm{ng} / \mathrm{ml}$ TNF $\alpha$ for 6 or 24 hours (black bars), as indicated, in the absence (a) or the presence (b) of serum. The data are expressed as pg/10 cells, and values are the mean $\pm S D$ of at least three independent experiments in duplicate.

KCs secreted basal level of all the molecules analyzed and the treatment with TNF $\alpha$ induced a further increase of almost all of them (Figures 5(a) and 5(b)). All the CXC chemokine family members appeared to be highly upregulated, reaching a value for the CXCL8/IL8 more than $20,000 \mathrm{pg} / 10^{6}$ cells (Figure 5(a)). Among the CC chemokines, only CCL2 showed approximately fivefold increase above controls. Of note, high concentration of growth factors, as TGF $\alpha$ and GM-CSF, was detected in medium of primary KCs stimulated with TNF $\alpha$ (Figure 5(b)).

\section{Discussion}

Keratinocytes are active players in epidermal repair and in the skin's immune defense through the secretion of growth factors, cytokines, and chemokines. To facilitate and standardize the in vitro studies on $\mathrm{KCs}$, we investigated the use of HaCaT cells as a suitable model to follow the release of cutaneous inflammatory and repair mediators in response to TNF $\alpha$ or IL- $1 \beta$, and in relation to different culture conditions and differentiation levels.

$\mathrm{HaCaT}$ cells are a long-lived, spontaneously immortalized human KC line, which exhibit basal cell properties and display substantial changes in response to two wellestablished in vitro prodifferentiating agents: the increase in cell density, as a function of time in culture, and extracellular $\mathrm{Ca}^{2+}$ concentration.

The switch from low to high extracellular $\mathrm{Ca}^{2+}$ concentration is considered not only a major regulator of the $\mathrm{KC}$ differentiation, but also of their proliferation both in vitro and in vivo. $\mathrm{A} \mathrm{Ca}^{2+}$ gradient within the epidermis promotes the sequential differentiation of $\mathrm{KC}$ from the basal layer to 

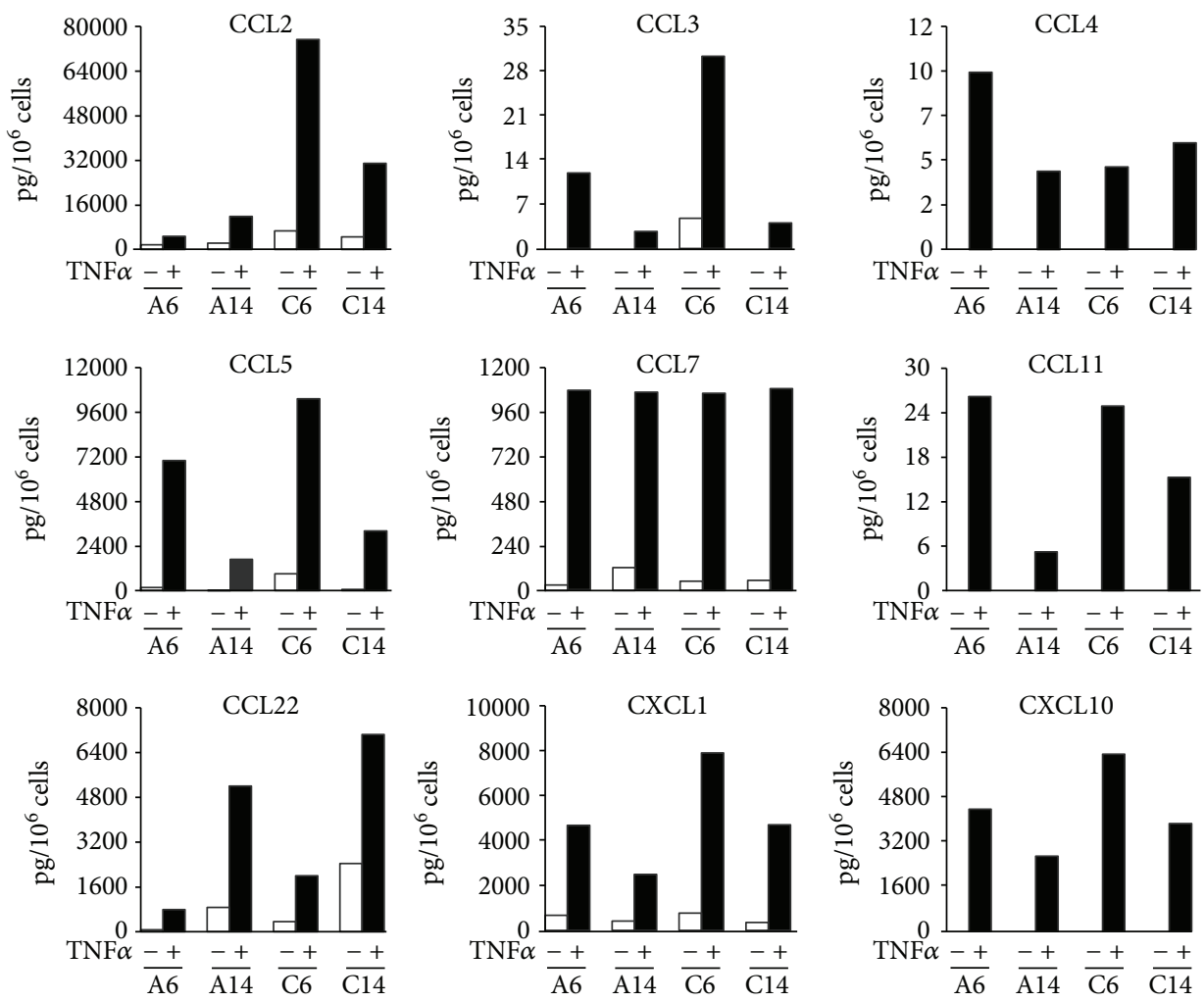

(a)
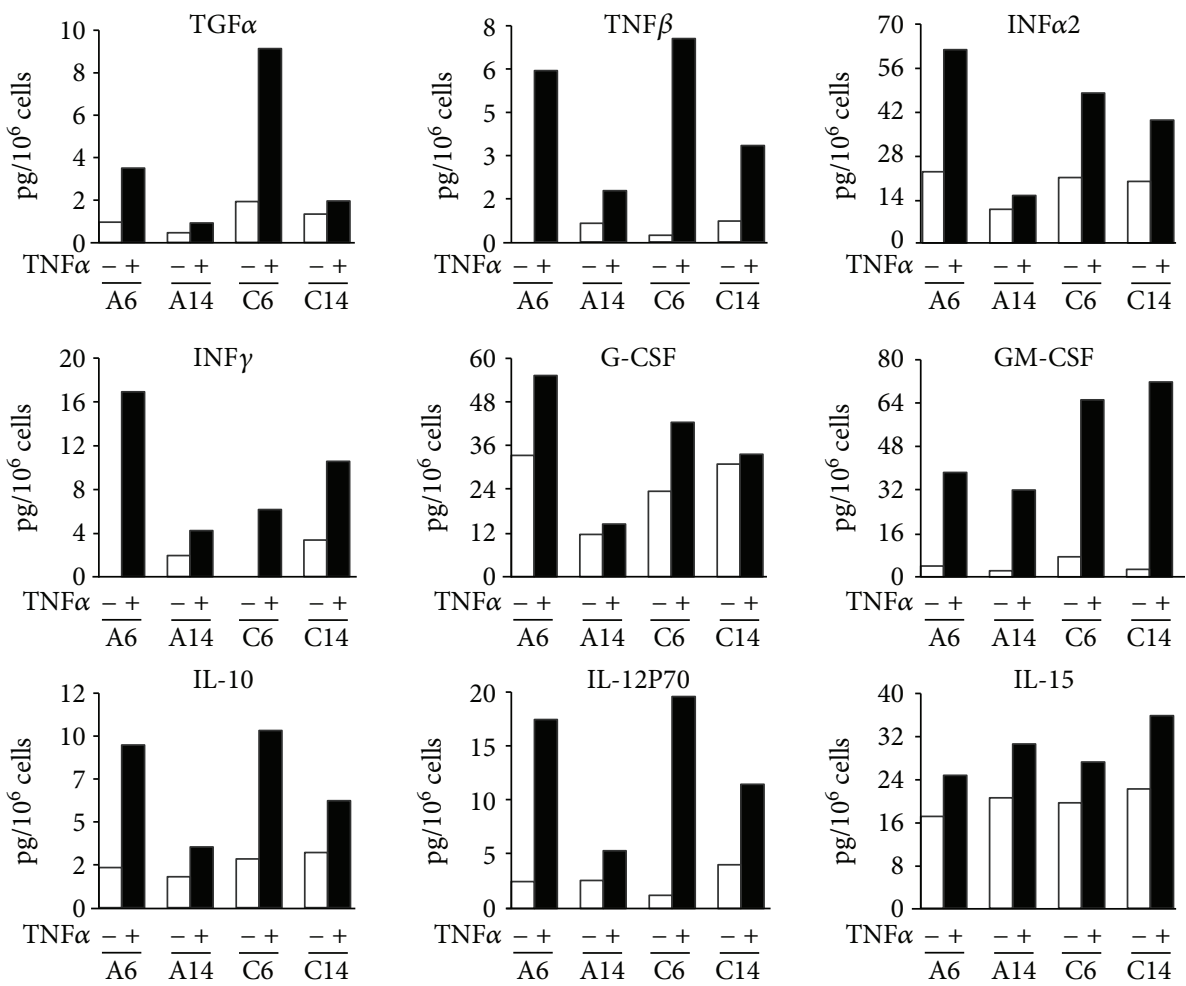

(b)

FIgURe 4: Bioplex multiplex system analysis of supernatants from HaCaT cells stimulated by TNF $\alpha$ during cell differentiation. The amount of chemokines (a), cytokines, and growth factors (b) was measured by Multiplex system technology in the supernatants of HaCaT cells plated at $1.0 \times 10^{4} \mathrm{cells} / \mathrm{cm}^{2}$, grown in low (a) and high (c) $\mathrm{Ca}^{2+}$-containing medium for 6 (A6 and C6) and 14 (A14 and C14) days (white bars), and treated with $10 \mathrm{ng} / \mathrm{ml} \mathrm{TNF} \alpha$ for 48 hours (black bars) in a serum-free medium. The data are expressed as pg/10 $0^{6}$ cells. 

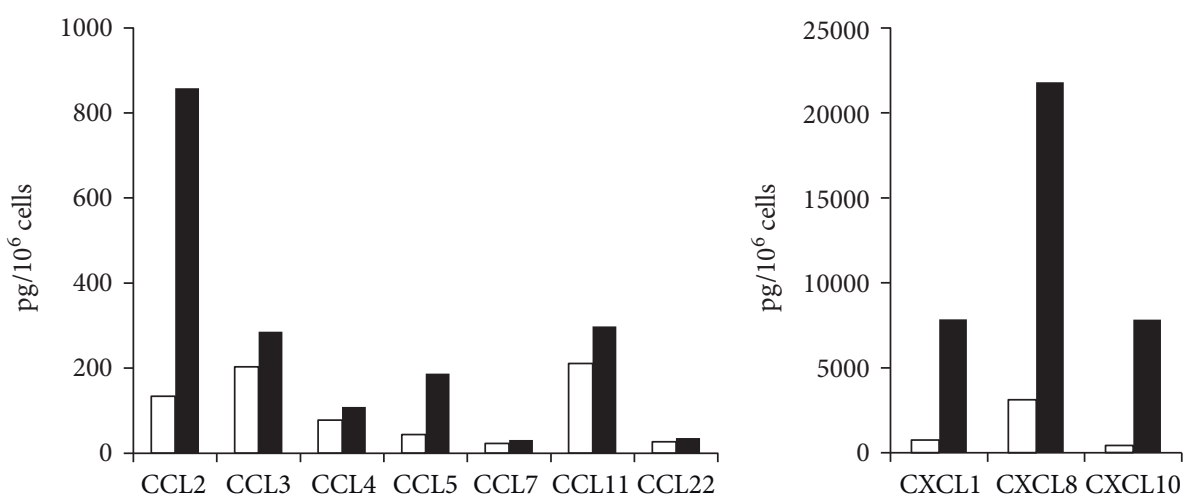

(a)
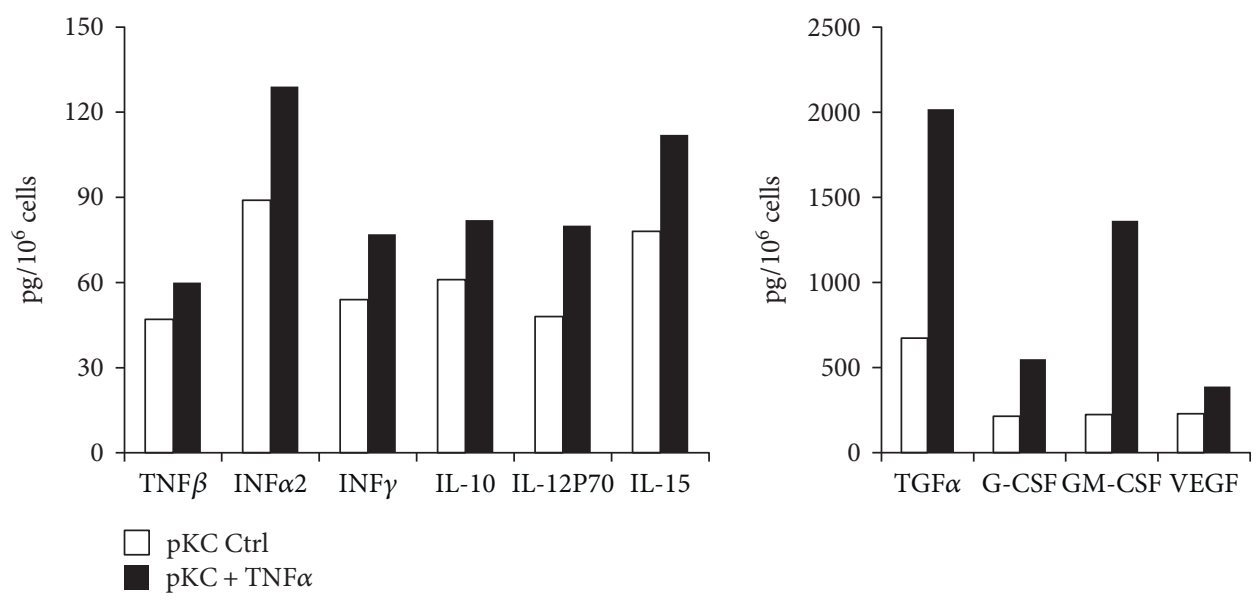

(b)

Figure 5: In vitro release of cytokines, chemokines, and growth factors from primary adult human keratinocytes stimulated by TNF $\alpha$. The amount of chemokines (a), of cytokines, and of growth factors (b) was measured by Multiplex system technology in the supernatants of primary adult human keratinocytes $(\mathrm{pKC})$ plated at the same density $\left(8-10 \times 10^{4}\right.$ cells $\left./ \mathrm{cm}^{2}\right)$ and grown in low Ca ${ }^{2+}$-containing medium (white bars). The treatment with $10 \mathrm{ng} / \mathrm{ml} \mathrm{TNF} \alpha$ was carried out for 48 hours in a serum-free medium when cells were $60-70 \%$ confluent (black bars). The data are expressed as $\mathrm{pg} / 10^{6}$ cells.

the stratum corneum. Moreover, $\mathrm{Ca}^{2+}$ regulates the formation of desmosomes, adherent junctions, and tight junctions. The latter maintain cell-cell adhesion and play an important role in intracellular signaling that regulate $\mathrm{Ca}^{2+}$ levels and cell cycle arrest, critical for the differentiation process [12].

With this in mind, we first tested the differentiation potential of $\mathrm{HaCaT}$ cells in response to the increase in cell density and in extracellular $\mathrm{Ca}^{2+}$ concentration, by evaluating the expression of three markers of differentiation, namely K14, whose expression is restricted to the basal layer, $\mathrm{K} 10$, and involucrin that indicate a more differentiated phenotype. Our data (Figure 1 and Table 1S) confirm and extend previous observations that the increase in cell density and extracellular $\mathrm{Ca}^{2+}$ concentration favors $\mathrm{HaCaT}$ differentiation [14-17]. HaCaT cells remain in the basal state (high levels of K14) when maintained in low $\mathrm{Ca}^{2+}$ conditions and less than $80 \%$ confluent (A6), while they begin to differentiate expressing high levels of $\mathrm{K} 10$ and involucrin after a long-term culture (A14), that is when, although maintained in low $\mathrm{Ca}^{2+}$ medium, they are overconfluent. Different from previous observations, we noticed that $\mathrm{HaCaT}$ cells maintain their basal phenotype also when the cells are cultured in high
$\mathrm{Ca}^{2+}$ conditions, but at less than $80 \%$ confluence. This observation suggests that, although extracellular $\mathrm{Ca}^{2+}>0.1 \mathrm{mM}$ appears to be a major regulator of $\mathrm{HaCaT}$ differentiation, the role of cell density is also relevant and it might have been underestimated in previous in vitro studies.

Moreover, in our study, the Western blot analysis of K10 and involucrin expression showed that when $\mathrm{HaCaT}$ cells are maintained in high $\mathrm{Ca}^{2+}$ condition, the overconfluence promotes a slight decrease of both K10 and involucrin levels and a weak increase of K14. Although this observation may be a consequence of the lower density of $\mathrm{C} 14$ with respect to $\mathrm{A} 14$, these data are in agreement with the changes of $\mathrm{Ca}^{2+}$ and confluence-dependent expression of $\mathrm{K} 1$, a biomarker of more differentiated cells [20], but not with the changes reported for the transglutaminase biomarker [17]. Altogether, this emphasizes the importance of a careful monitoring of differentiation marker expression during longterm culture of $\mathrm{HaCaT}$ cells and of standardization of the culture conditions.

The effect of the $\mathrm{Ca}^{2+}$ switch on the proliferation of $\mathrm{HaCaT}$ cells is poorly investigated. Our viability assays and cell counts highlight that the extracellular $\mathrm{Ca}^{2+}$ concentration 
strongly influences the proliferative ability of $\mathrm{HaCaT}$ cells. Up to day 2 of culture, no differences in the proliferation rate of $\mathrm{HaCaT}$ cells grown in low or high $\mathrm{Ca}^{2+}$ medium were seen, whereas a difference in the growth rate was evident in low $\mathrm{Ca}^{2+}$ medium starting from day 6 , which became significantly higher at day 14 . These findings are at variance of those showing a progressive, time-dependent increase of $\mathrm{HaCaT}$ proliferation in high $\mathrm{Ca}^{2+}$ medium [14]. A possible explanation could be the higher extracellular $\mathrm{Ca}^{2+}$ concentration used in the present study $(1.8 \mathrm{mM})$ compared to $1.2 \mathrm{mM}$ in [14]. In fact, it has been demonstrated that only an increase in intracellular $\mathrm{Ca}^{2+}$ concentration above $1.5 \mathrm{mM}$ results in a reduced growth rate [21].

In the second part of this study, $\mathrm{HaCaT}$ cells, cultured in low or high $\mathrm{Ca}^{2+}$ medium for different lengths of time, were used to investigate the release of CXCL8/IL8, VEGF, and MMP-9 in response to two proinflammatory stimuli, TNF $\alpha$, and IL-1 $\beta$. These cytokines were chosen for their predominant role in the pathogenesis of skin inflammation, since they both regulate genes previously shown to be specifically overexpressed in psoriasis [10,22-24]. Our results show that the release of CXCL8/IL8, VEGF, and MMP-9 was higher in HaCaT cell basal state (A6-C6) compared to more differentiated cells (A14-C14). $\mathrm{Ca}^{2+}$ concentrations slightly enhanced the secretion of these mediators, especially when IL- $1 \beta$ was used as proinflammatory stimulus; this effect could be partially explained by the activation of the $\mathrm{Ca}^{2+}$ responsive promoter of activator protein (AP)-1 [25].

The presence of serum reduced the $\mathrm{TNF} \alpha$-induced release of MMP-9 and enhanced the VEGF secretion, both at basal and stimulated levels. As previously reported, growth factors derived from fetal calf serum may influence a variety of parameters involved in $\mathrm{KC}$ proliferation, differentiation, and wound healing processes [26-28]. Based on these results, we strongly suggest that serum should not be used when the proinflammatory mediators, VEGF, or MMP-9, are assayed. This should be extended also to the assays using normal human KC.

Several papers demonstrated that $\mathrm{TNF} \alpha$ in KC regulates different genes involved in inflammation and angiogenesis, such as IL-1, ICAM-1, VEGF $[29,30]$, TGF- $\beta$, chemokines (CCL20, CCL27, CCL5, CCL2, CXCL10, and CXCL11), and members of the CXCL8 family, including CXCL1, CXCL2, and CXCL3 [10, 22, 23]. Therefore, using the Multiplex technology, we evaluated the effect of $\mathrm{Ca}^{2+}$ concentration and cellular density on the secretion of different cytokines, chemokines, and growth factors in $\mathrm{HaCaT}$ cell line. All the analyzed parameters were upregulated to a great extent by TNF $\alpha$ at day 6 in comparison to day 14; only CCL22/MDC seemed to be preferentially released in more differentiated HaCaT cells. CCL4, INF $\alpha 2$, INF $\gamma$, and G-CSF had a higher release in low $\mathrm{Ca}^{2+}$ condition, whereas, on the opposite, in high $\mathrm{Ca}^{2+}$ concentration, a comparable or higher secretion of CCL2, CCL3, CCL5, CCL7, CCL11, CCL22, CXCL1, CXCL10, TGF $\alpha$, TNF- $\beta$, IL-10, and IL-15 was seen. To summarize, both longterm culture and $\mathrm{Ca}^{2+}$ concentration in the medium affect the ability of $\mathrm{HaCaT}$ cells to release chemokines and growth factors.
Finally, to validate $\mathrm{HaCaT}$ cells as a reliable model to dissect the inflammatory/repair response of human KCs, we measured the release of inflammatory mediators in primary nonlesional epidermal KCs obtained from psoriatic patients. These cells were assayed in low $\mathrm{Ca}^{2+}$ medium and in the absence of serum.

The levels of the CXC family of chemokines, induced by TNF $\alpha$ on human KCs (CXCL1, CXCL8, and CXCL10) correlated relatively well to the values released by $\mathrm{HaCaT}$ cells in low $\mathrm{Ca}^{2+}$, considering the fold induction. Similar results were obtained on growth factors released (TGF $\alpha$, G-CSF, GMCSF, and VEGF). Not so close was the correlation with the CC family of chemokines some of which (CCL4, CCL5, CCL7, and CCL11) were highly released in A6 and C6 $\mathrm{HaCaT}$ cells, but quite low in normal human KCs; CCL2 was higher in $\mathrm{C} 6 \mathrm{HaCaT}$ as in normal KCs, whereas CCL3 was similar. Our results also show that $\mathrm{HaCaT}$ cells especially at day 14 of culture produce more CCL22/MDC than normal human KCs, thus confirming previously published data $[31,32]$. This is not the first time that a differential release of chemokines is described in primary human KCs or $\mathrm{HaCaT}$ cells stimulated with exogenous stimuli. Data in the literature reported that CXCL10 and IL8 were released to a similar extent by both cell types, while CXCL9 and CCL20 were more efficiently produced by primary human KCs [33].

In conclusion, this study is the first report where several variables, all together, including the influence of $\mathrm{Ca}^{2+}$ concentration, the cell density, the differentiation state, and the presence of serum, were considered as factors that may influence release of proinflammatory mediators by KCs. Our results support the use of $\mathrm{HaCaT}$ cell line, under carefully optimized in vitro condition, as a reliable model, with respect to normal KCs, to screen for new anti-inflammatory compounds for skin diseases. Indeed, $\mathrm{HaCaT}$ cell line has been successfully used for studying those pathologies in which skin keratinocytes are involved, such as infectious diseases or tumors, or as in vitro carcinogenesis model of human skin [34]. By modulating $\mathrm{Ca}^{2+}$ concentration in culture medium and maintaining $80 \%$ confluence, $\mathrm{HaCaT}$ cells are in the conditions of producing cytokines at medium/low levels (A6 condition) or at medium/high levels (C6 condition) as expected in highly activated KCs from skin lesions. This in vitro system has the advantage of being reproducible and reliable and definitively less invasive and with less variability than KC from skin biopsies. However, one of the drawbacks is the inability of reproducing the skin complexity and cellular heterogeneity in basal or inflammatory conditions. 2D-3D culture systems have been proposed which mimic the differentiation process [35]. It cannot be excluded that in a relatively short time we may have available $3 \mathrm{D}$ culture systems in which several cell lineages KC, immune cells, and fibroblasts will be cocultured to ensure a better reproduction of the skin microenvironment.

\section{Abbreviations}

CCL: $\quad$ C-C motif chemokine ligand

CXCL: $\quad$ C-X-C motif chemokine ligand

CX3CL: C-X3-C motif chemokine ligand 
G-CSF: Granulocyte-colony stimulating factor

GM-CSF: Granulocyte-macrophage colony-stimulating factor

IFN: Interferon

IL: Interleukin

K: $\quad$ Keratin

KC: $\quad$ Keratinocyte

MMP-9: Matrix metalloproteinase-9

TGF $\alpha$ : Transforming growth factor alpha

TNF $\alpha$ : Tumor necrosis factor alpha

TNF $\beta$ : Tumor necrosis factor beta

VEGF: Vascular endothelial growth factor.

\section{Disclosure}

Yolanda Corbett's present address is Dipartimento di Bioscienze, Università degli Studi di Milano, Via Giovanni Celoria 26, 20133 Milano, Italia.

\section{Conflicts of Interest}

The authors state no conflict of interest.

\section{Acknowledgements}

The authors thank Professor Dr. Petra Boukamp and Dr. Norbert Fusenig from Deutsches Krebsforschungszentrum, Stiftung des öffentlichen Rechts (German Cancer Research Center), Im Neuenheimer Feld 280, D-69120 Heidelberg, Germany, for providing $\mathrm{HaCaT}$ cell line. The financial support of the Ministero dell'Istruzione, dell'Università e della Ricerca (PRIN, grant 2010C2LKKJSKINFLAM) to Donatella Taramelli, Angela Gismondi, and Stefano Calvieri is acknowledged. Donatella Taramelli acknowledges the support from the COST Action CM1307. The work was partially supported by Fondazione Cariplo (HyWoNNa project grant to MDA).

\section{Supplementary Materials}

Supplementary 1. Table 1S: Cell recovery and protein content of $\mathrm{HaCaT}$ cells grown in low (A) or high (C) $\mathrm{Ca}^{2+}$ medium for 6 (A6, C6) or 14 (A14, C14) days.

Supplementary 2. Figure S1: Changes in HaCaT cell morphology during cell differentiation.

Supplementary 3. Figure S2: In vitro release of CXCL8/IL8, VEGF, and MMP-9 from HaCat cells stimulated by IL- $1 \beta$ during cell differentiation.

\section{References}

[1] A. Baroni, E. Buommino, V. De Gregorio, E. Ruocco, V. Ruocco, and R. Wolf, "Structure and function of the epidermis related to barrier properties," Clinics in Dermatology, vol. 30, no. 3, pp. 257-262, 2012.

[2] K. H. Hanel, C. Cornelissen, B. Luscher, and J. M. Baron, "Cytokines and the skin barrier," International Journal of Molecular Sciences, vol. 14, no. 4, pp. 6720-6745, 2013.
[3] J. Henry, E. Toulza, C. Y. Hsu et al., "Update on the epidermal differentiation complex," Frontiers in Bioscience, vol. 17, no. 1, pp. 1517-1532, 2012.

[4] E. Proksch, J. M. Brandner, and J. M. Jensen, "The skin: an indispensable barrier," Experimental Dermatology, vol. 17, pp. 1063-1072, 2008.

[5] F. O. Nestle, P. Di Meglio, J. Z. Qin, and B. J. Nickoloff, "Skin immune sentinels in health and disease," Nature Reviews Immunology, vol. 9, no. 10, pp. 679-691, 2009.

[6] M. M. Suter, K. Schulze, W. Bergman, M. Welle, P. Roosje, and E. J. MÃ $1 / 4$ ller, "The keratinocyte in epidermal renewal and defence," Veterinary Dermatology, vol. 20, no. 5-6, pp. 515532, 2009.

[7] C. Albanesi, O. De Pita, and G. Girolomoni, "Resident skin cells in psoriasis: a special look at the pathogenetic functions of keratinocytes," Clinics in Dermatology, vol. 25, no. 6, pp. 581-588, 2007.

[8] S. Pastore, F. Mascia, and G. Girolomoni, "The contribution of keratinocytes to the pathogenesis of atopic dermatitis," European Journal of Dermatology, vol. 16, no. 2, pp. 125-131, 2006.

[9] C. Albanesi, "The role of keratinocytes in inflammatory skin diseases," Advances in Psoriasis and Inflammatory Skin Diseases, vol. 1, pp. 47-58, 2009.

[10] C. Albanesi, C. Scarponi, M. L. Giustizieri, and G. Girolomoni, "Keratinocytes in inflammatory skin diseases," Current Drug Target-Inflammation \& Allergy, vol. 4, no. 3, pp. 329-334, 2005.

[11] D. D. Bikle, A. Ratnam, T. Mauro, J. Harris, and S. Pillai, "Changes in calcium responsiveness and handling during keratinocyte differentiation. Potential role of the calcium receptor," The Journal of Clinical Investigation, vol. 97, no. 4, pp. 1085-1093, 1996.

[12] D. D. Bikle, Z. Xie, and C. L. Tu, "Calcium regulation of keratinocyte differentiation," Expert Review of Endocrinology \& Metabolism, vol. 7, pp. 461-472, 2012.

[13] N. Schurer, A. Kohne, V. Schliep, K. Barlag, and G. Goerz, "Lipid composition and synthesis of HaCaT cells, an immortalized human keratinocyte line, in comparison with normal human adult keratinocytes," Experimental Dermatology, vol. 2, no. 4, pp. 179-185, 1993.

[14] L. Micallef, F. Belaubre, A. Pinon et al., "Effects of extracellular calcium on the growth-differentiation switch in immortalized keratinocyte HaCaT cells compared with normal human keratinocytes," Experimental Dermatology, vol. 18, no. 2, pp. 143$151,2009$.

[15] P. Boukamp, R. T. Petrussevska, D. Breitkreutz, J. Hornung, A. Markham, and N. E. Fusenig, "Normal keratinization in a spontaneously immortalized aneuploid human keratinocyte cell line," The Journal of Cell Biology, vol. 106, no. 3, pp. 761-771, 1988.

[16] A. F. Deyrieux and V. G. Wilson, "In vitro culture conditions to study keratinocyte differentiation using the $\mathrm{HaCaT}$ cell line," Cytotechnology, vol. 54, no. 2, pp. 77-83, 2007.

[17] O. Garach-Jehoshua, A. Ravid, U. A. Liberman, J. Reichrath, T. Glaser, and R. Koren, "Upregulation of the calciumdependent protease, calpain, during keratinocyte differentiation," British Journal of Dermatology, vol. 139, no. 6, pp. 950-957, 1998.

[18] T. Mosmann, "Rapid colorimetric assay for cellular growth and survival: application to proliferation and cytotoxicity assays," Journal of Immunological Methods, vol. 65, no. 1-2, pp. 55-63, 1983. 
[19] O. H. Lowry, N. J. Rosebrough, A. L. Farr, and R. O. S. E. J. RANDALL, "Protein measurement with the Folin phenol reagent," Journal of Biological Chemistry, vol. 193, no. 1, pp. 265-275, 1951.

[20] A. Capone, V. Visco, F. Belleudi et al., "Up-modulation of the expression of functional keratinocyte growth factor receptors induced by high cell density in the human keratinocyte HaCaT cell line," Cell Growth \& Differentiation, vol. 11, no. 11, pp. 607-614, 2000.

[21] M. Sakaguchi, M. Miyazaki, M. Takaishi et al., "S100C/A11 is a key mediator of $\mathrm{Ca}^{2+}$-induced growth inhibition of human epidermal keratinocytes," The Journal of Cell Biology, vol. 163, no. 4, pp. 825-835, 2003.

[22] T. Banno, A. Gazel, and M. Blumenberg, "Effects of tumor necrosis factor- $\alpha$ (TNF $\alpha)$ in epidermal keratinocytes revealed using global transcriptional profiling," Journal of Biological Chemistry, vol. 279, no. 31, pp. 32633-32642, 2004.

[23] C. Albanesi and S. Pastore, "Pathobiology of chronic inflammatory skin diseases: interplay between keratinocytes and immune cells as a target for anti-inflammatory drugs," Current Drug Metabolism, vol. 11, no. 3, pp. 210-227, 2010.

[24] S. Yano, T. Banno, R. Walsh, and M. Blumenberg, "Transcriptional responses of human epidermal keratinocytes to cytokine interleukin-1," Journal of Cellular Physiology, vol. 214, no. 1, pp. 1-13, 2008.

[25] F. Elsholz, C. Harteneck, W. Muller, and K. Friedland, "Calcium - a central regulator of keratinocyte differentiation in health and disease," European Journal of Dermatology, vol. 24, no. 6, pp. 650-661, 2014.

[26] G. Altankov, J. Hecht, and N. Dimoudis, "Serum-free cultured keratinocytes fail to organize fibronectin matrix and possess different distribution of beta-1 integrins," Experimental Dermatology, vol. 10, no. 2, pp. 80-89, 2001.

[27] G. Hubner and S. Werner, "Serum growth factors and proinflammatory cytokines are potent inducers of activin expression in cultured fibroblasts and keratinocytes," Experimental Cell Research, vol. 228, no. 1, pp. 106-113, 1996.

[28] R. Pfundt, M. Wingens, M. Bergers, M. Zweers, M. Frenken, and J. Schalkwijk, "TNF- $\alpha$ and serum induce SKALP/elafin gene expression in human keratinocytes by a p38 MAP kinase-dependent pathway," Archives of Dermatological Research, vol. 292, no. 4, pp. 180-187, 2000.

[29] J. N. Barker, R. S. Mitra, C. E. Griffiths, V. M. Dixit, and B. J. Nickoloff, "Keratinocytes as initiators of inflammation," The Lancet, vol. 337, no. 8735, pp. 211-214, 1991.

[30] S. Yoshida, M. Ono, T. Shono et al., "Involvement of interleukin-8, vascular endothelial growth factor, and basic fibroblast growth factor in tumor necrosis factor alpha-dependent angiogenesis," Molecular and Cellular Biology, vol. 17, no. 7, pp. 4015-4023, 1997.

[31] C. Yano, H. Saeki, M. Komine et al., "Mechanism of macrophage-derived chemokine/CCL22 production by HaCaT keratinocytes," Annals of Dermatology, vol. 27, no. 2, pp. 152-156, 2015.

[32] M. Kobayashi, T. Shimauchi, R. Hino, and Y. Tokura, "Roxithromycin downmodulates Th2 chemokine production by keratinocytes and chemokine receptor expression on Th2 cells: its dual inhibitory effects on the ligands and the receptors," Cellular Immunology, vol. 228, no. 1, pp. 27-33, 2004.
[33] F. Olaru and L. E. Jensen, "Chemokine expression by human keratinocyte cell lines after activation of toll-like receptors," Experimental Dermatology, vol. 19, no. 8, pp. e314-e316, 2010.

[34] N. E. Fusenig and P. Boukamp, "Multiple stages and genetic alterations in immortalization, malignant transformation, and tumor progression of human skin keratinocytes," Molecular Carcinogenesis, vol. 23, no. 3, pp. 144-158, 1998.

[35] L. Li, M. Fukunaga-Kalabis, and M. Herlyn, "The threedimensional human skin reconstruct model: a tool to study normal skin and melanoma progression," Journal of Visualized Experiments, no. 54, p. 54, 2011. 


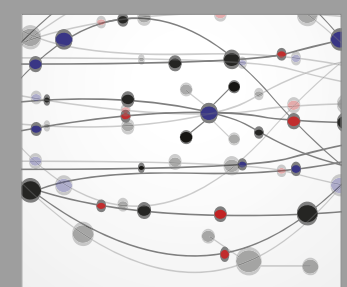

The Scientific World Journal
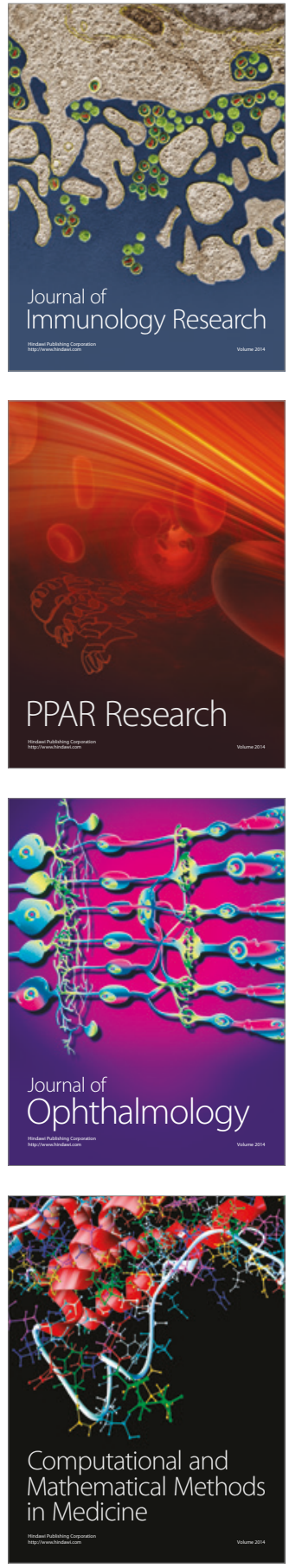

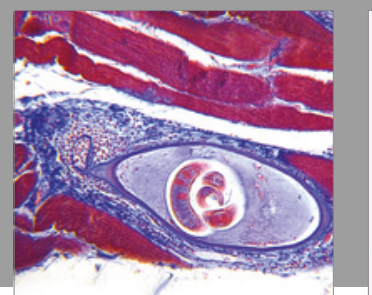

Gastroenterology Research and Practice
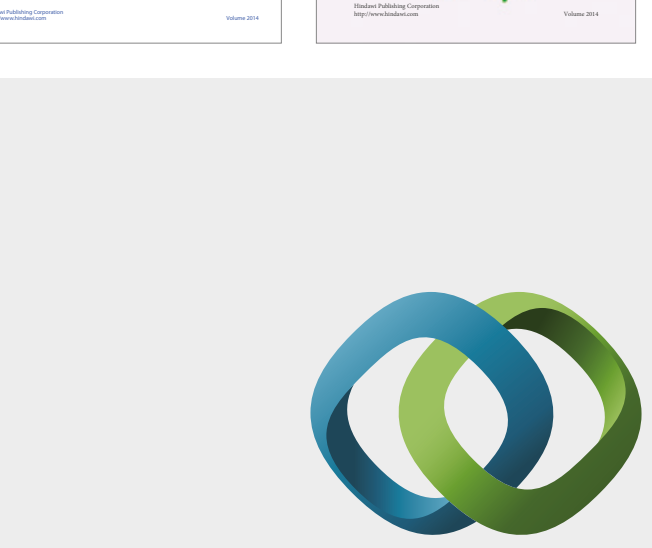

\section{Hindawi}

Submit your manuscripts at

https://www.hindawi.com
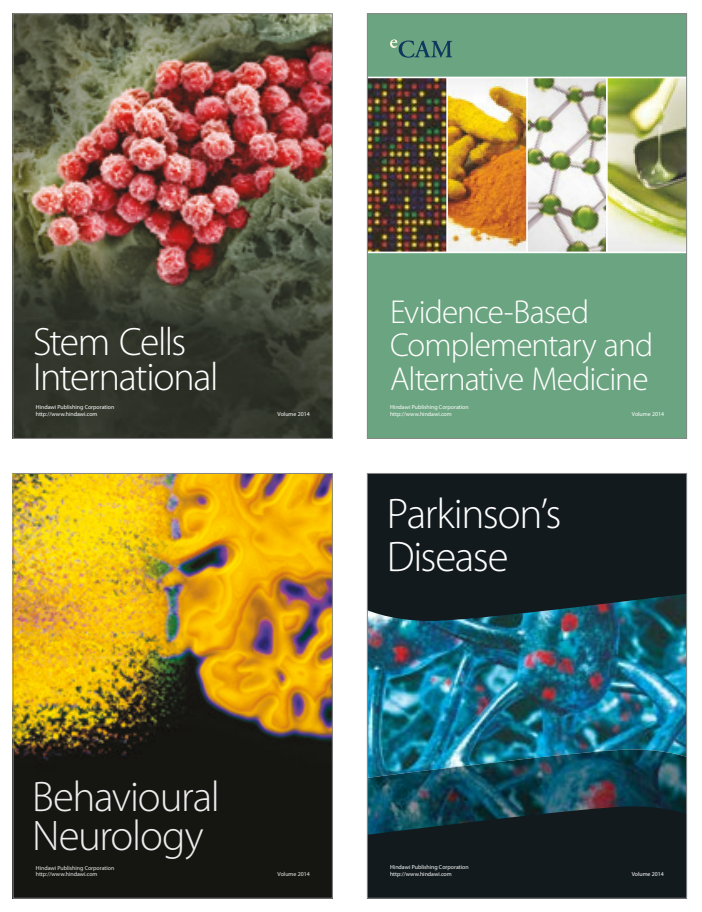
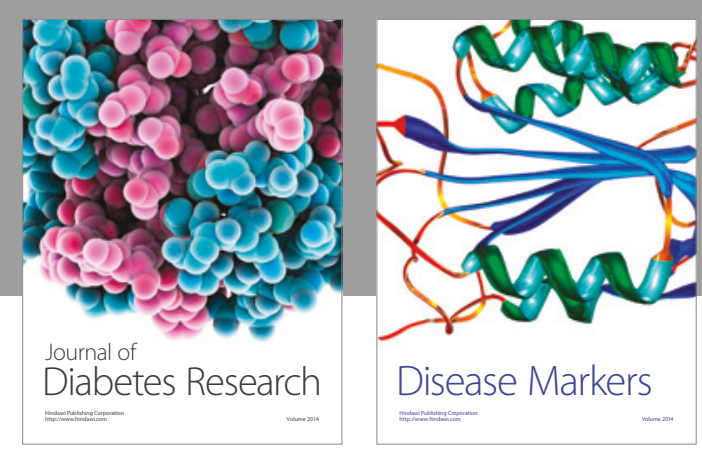

Disease Markers
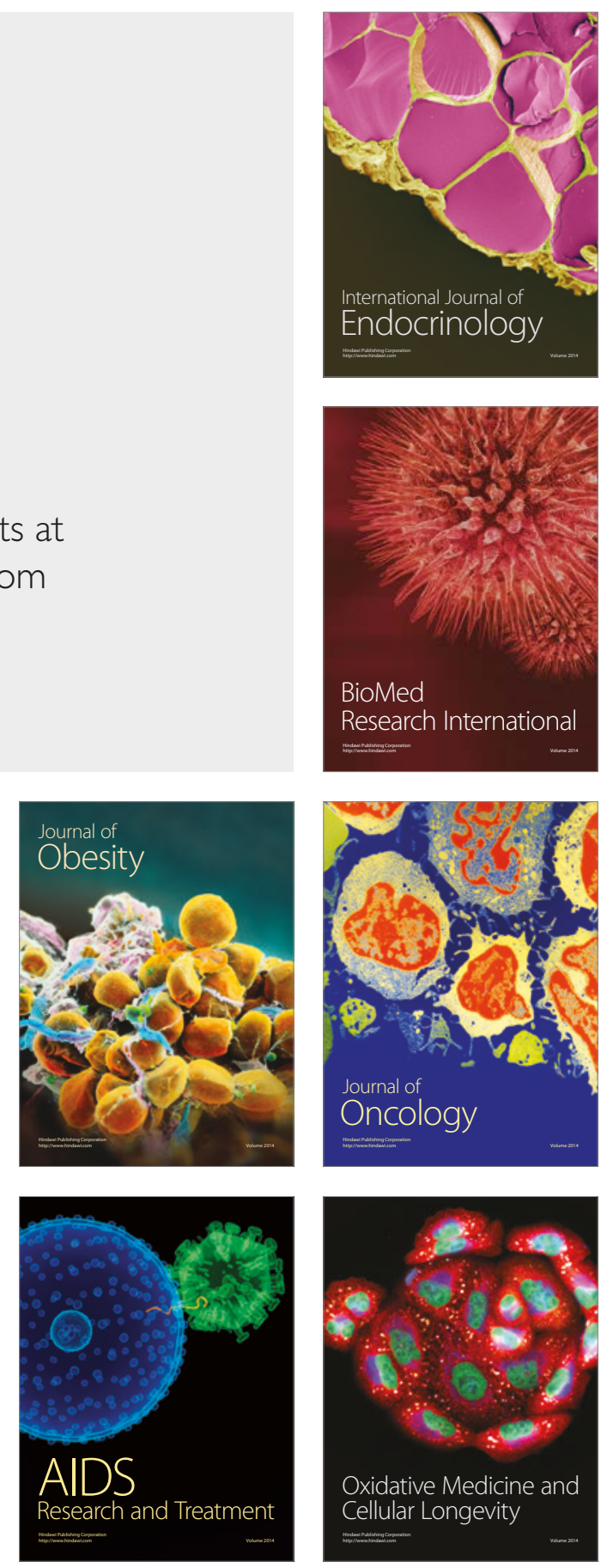